\title{
Stimulation of use of in-situ experiments in high voltage electron microscopes in advancing science and technology
}

\author{
Toru Imura \\ Department of Mechanical Engineering, Aichi Institute of Technology, Yagusa-cho. Toyota City, 470- \\ 03, Japan
}

(Received 31 January 1993; accepted 7 June 1993)

\begin{abstract}
At first, a brief historical sketch of the development of in-situ experiments in electron microscopes is made. Next, the merits of use of high voltage electron microscopy (HVEM) for carrying out in-situ experiments, and four types of effort made to improve the in-situ HVEM are described. Then, advantages of a newly developed STEM-mode HVEM of Nagoya university and possible applications of it are discussed. As for the applications of in-situ experiments made so far by the author's group, the research subjects particularly related to the studies of behavior of lattice defects are referred, and the results obtained on the mobility of edge and screw dislocations in bcc metals and alloys, and those on the temperature dependence of stacking-fault energies in fcc metals and alloys are illustrated. Further improvements and new fields of application of the in-situ HVEM are suggested.
\end{abstract}

\section{Introduction.}

Idea of in-situ experiment itself is nothing new. It stands on our hope to understand more in detail a particular phenomenon in nature by reproducing it hopefully in the analytical system being used in our laboratory to study the origin, process and mechanism of the phenomenon. This idea has been applied to study dynamic phenomena of great interest in various branches of science and technology. Microscopy has been one of the fruitful branches of its application.

Since 1960, about 60 high voltage electron microscopes (HVEMs) of maximum accelerating voltage higher than $500 \mathrm{kV}$ have been constructed in the world. By the development of these HVEMs, transmission observation of thick foil specimens of the order of $\mu \mathrm{m}$ thick became possible [1-3] and facilitated in-situ observations of behavior of lattice defects [4-9] and other structural entities as well as in-situ observations of radiation damages caused by high energy electrons and ion irradiation $[10,11]$. However, it should be recognized here that in the case of the behavior of, for instance, lattice defects like dislocations which accompany widely spread lattice strain, the density of defects and the behavior of them change greatly when one uses a thin foil specimen of the thickness of less than a critical value $[12,2,7]$. This is a big reason why HVEM is required to be developed. 


\section{In-situ experiments in HVEM.}

In the course of the development of HVEMs, various specimen treatment devices $[13,8]$ were constructed and a variety of specimen treatment could be applied to the specimen being examined in a controlled manner in a HVEM and the phenomenon being induced by such treatment could be observed directly.

In 1967, a TV-VTR system was introduced to HVEM in-situ experiments for the first time as an image recording system by our Nagoya group [4, 14-16] and continuous fast recording by this system of the images of dislocations moving under a controlled stress-strain condition was initiated $[4,6,7,17]$. Many useful and original informations have been obtained on the behavior, in particular, of lattice defects in various crystalline materials. Since then, this type of in-situ experiments in HVEM has been widely used all over the world and now it becomes a well-established useful technique in materials research.

In ordinary electron microscopy, observations are usually made with the specimen prepared before and after the dynamic process concerned. However, in in-situ experiments, dynamic observations of the specimen being treated in EM provide at least two merits: (1) no speculation is needed in analysing the sequence of events in a dynamic process and (2) information of the speed of dislocation motion and structure change can be obtained by observing the successive stages continuously. However, those observations become much more useful if the results obtained by those microscopic observations are directly correlated with the stage of macroscopic behavior of the specimen being examined. For such purposes, a new experimental technique was developed with an idea which enables one to make a direct correlation possible, for instance, between the behavior of dislocations and the macroscopic behavior or stage of the specimen represented by a point on the stress-strain curve by recording both of the dislocation behavior and the stress-strain curve simultaneously in parallel $[6,7,17,18]$. Of course, some size effects may be found, so that absolute values of load and elongation measured with a thin specimen may differ somewhat from those measured with bulky specimens and the accuracy of the measurement of cross-sectional area of the specimen for obtaining the applied stress is not so high as compared with bulky specimens, but even so, the technique described in the references [5] and [6] is good enough to make a direct correlation between the moving dislocation and the stress-strain state of the specimen with a reasonable accuracy. Figure 1 indicates a schematic representation of a complete assembly for carrying out HVEM in-situ straining experiments.

\section{Efforts made to develop HVEM in-situ experiments.}

3.1 EFFORTS TO IMPROVE THE TECHNIQUE OF IN-SITU ELECTRON MICROSCOPY - Four types of effort have been made at least so far to improve the technique of HVEM in-situ experiments:

1) the first is to develop new devices for specimen-treatment to facilitate those types of $i n$-situ experiment which were previously impossible or difficult to carry out. These specimen-treatments include (a) deformation, (b) heat-treatment (heating and cooling), (c) irradiation, (d) magnetic field, (e) flow of electricity, (f) vapour deposition, (g) interaction with environment, etc. Figure 2 indicates functional features of various in-situ specimen-treatment devices developed by groups at Nagoya and Osaka universities in Japan [13]. Figure 3 illustrates schematic drawings of a low temperature in-situ straining device (a), and an in-situ fatigue testing device (b) developed by the author's group [19].

2) the second is to improve the resolution of in-situ electron microscopy. This includes the improvement of time- and space- resolution of a dynamic recording system [20, 21] (brightness and resolution of fluorescent material and TV-VTR system [20]), and application of various 


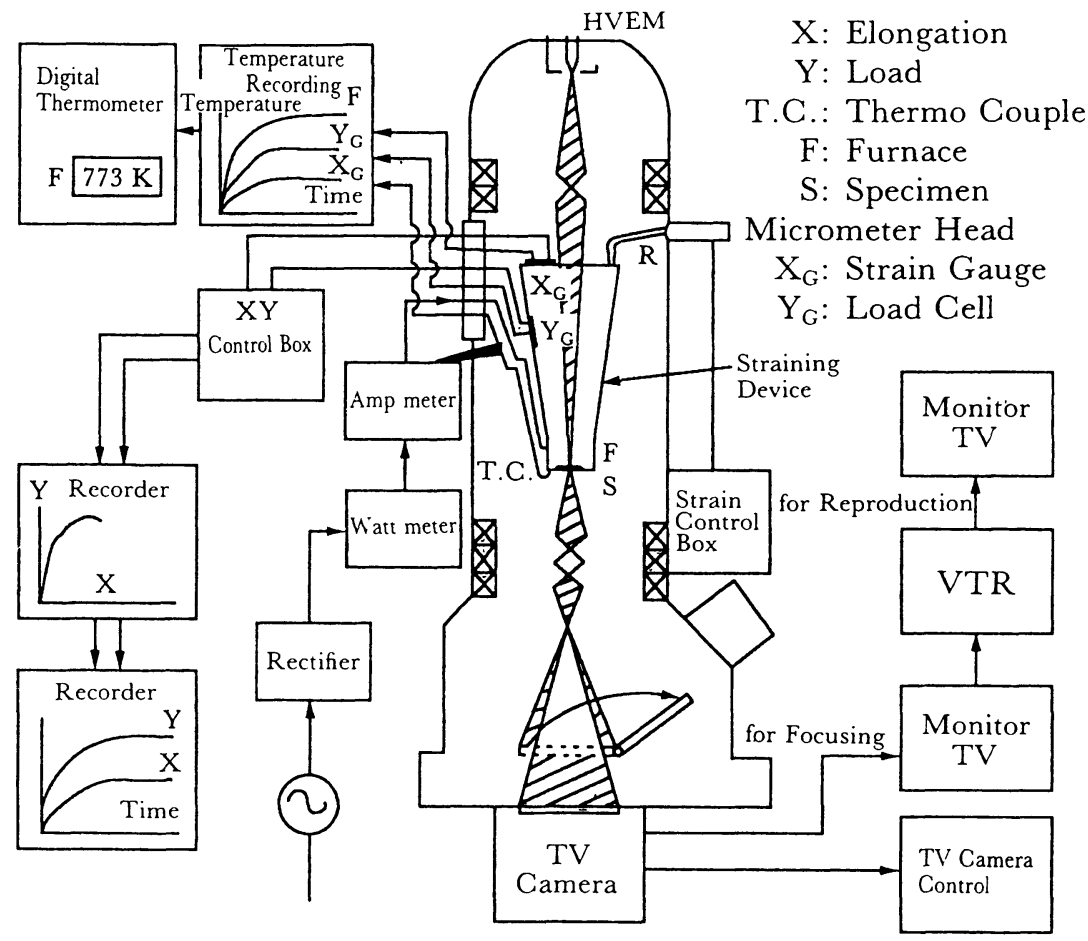

Fig. 1. - Schematic representation of a complete setup for carrying out HVEM in-situ straining experiments.

high-resolution techniques [20,21] such as weak-beam technique (WB), and crystal structure imaging technique (CSI) etc., and signal manipulation (H. Hibino et al. in Proc. 11th Int. Cogr. Kyoto, 1986) for in-situ electron microscopy. Figure 4 illustrates two types of TV-VTR recording system, (a) indirect type and (b) direct type.

3 ) the third is to reduce the electron irradiation damages of a specimen during observation by using a STEM-mode HVEM and also a detector of high detecting efficiency [20-22]. One usually observes an apparent reduction of electron-irradiation damage being produced during HVCTEM observation of a very thin foil specimen due to diffusion of damages to very close sinks, i.e., free surfaces. In addition, the damages being produced by a very fine scanning beam of $0.5 \mathrm{~nm}$ in diameter in the case of our HV-STEM diffuse away from the irradiated spot to free surfaces and to its surrounding matrix before the beam comes back to the same spot, so that the accumulation of damages at the same place becomes less than the HV-CTEM case. Quantitative data will be published elsewhere by M. Kiritani.

4) the fourth is to equip a detector like EELS for analyzing elements included in a limited area of a thick foil specimen [20-22].

3.2 DEVELOPMENT OF A STEM-MODE HVEM - A scanning transmission electron microscope has many attractive features which are particularly useful when this mode of electron microscope is used for in-situ observations at higher accelerating voltages. Figure 5 indicates those attractive features of HV-STEM as compared with those of HV-CTEM (Conventional Transmission Electron Microscope). Among those, possibility of damage-rate reduced dynamic observations of a thicker specimen is most attractive. 


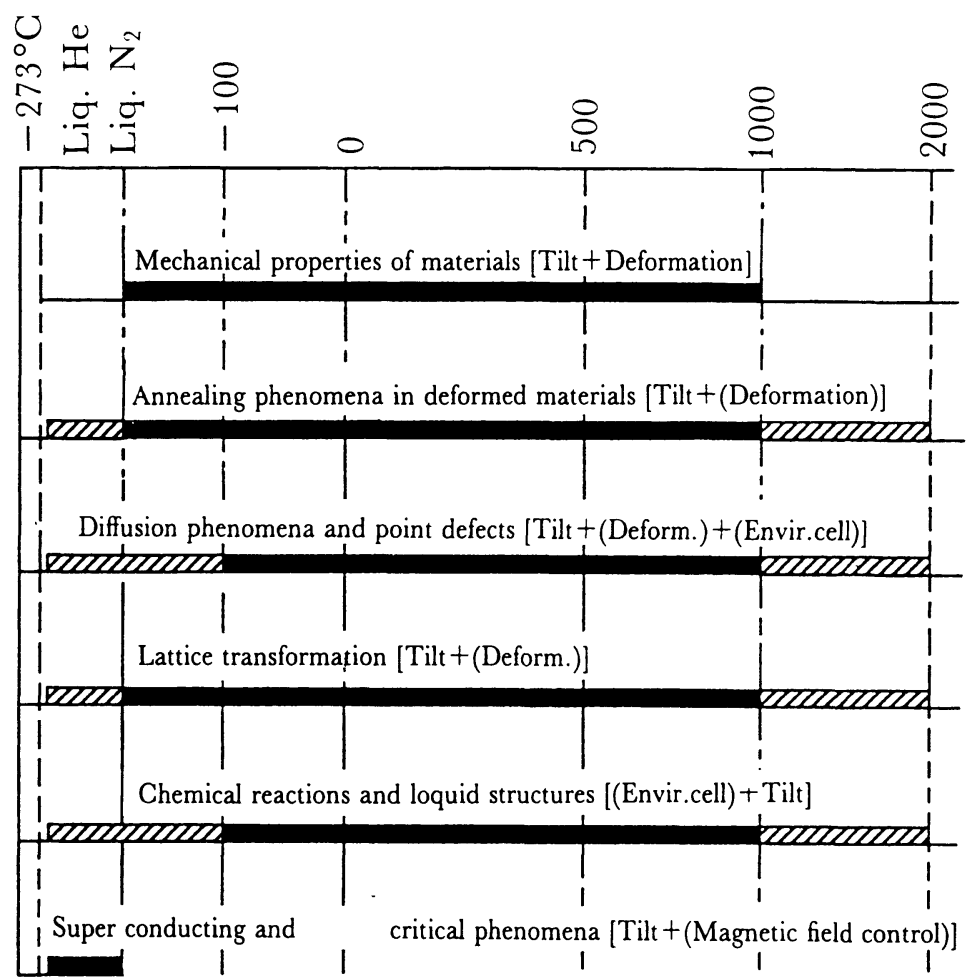

Fig. 2. - Functional features of various in-situ specimen-treatment devices. Usable temperature range extends to the shaded area when the function enclosed in bracket is excluded.

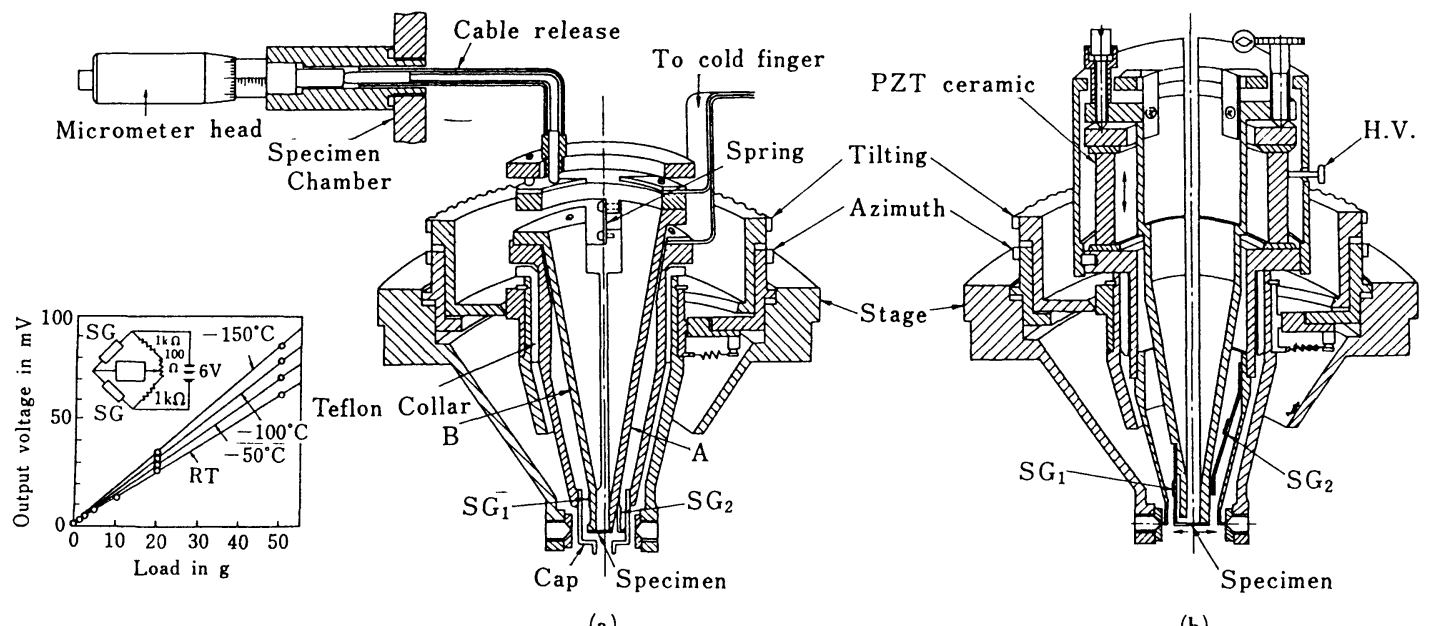

(a)

(b)

Fig. 3. - Schematic drawings of a low temperature $(\sim 77 \mathrm{~K})$ in-situ straining device and an in-situ fatigue testing device.

A HV-STEM, whose maximum accelerating voltage is $1250 \mathrm{kV}$ and which equips an EELS analyzer, was constructed by the group of Nagoya university with a cooperation of Hitachi Ltd. Figure 

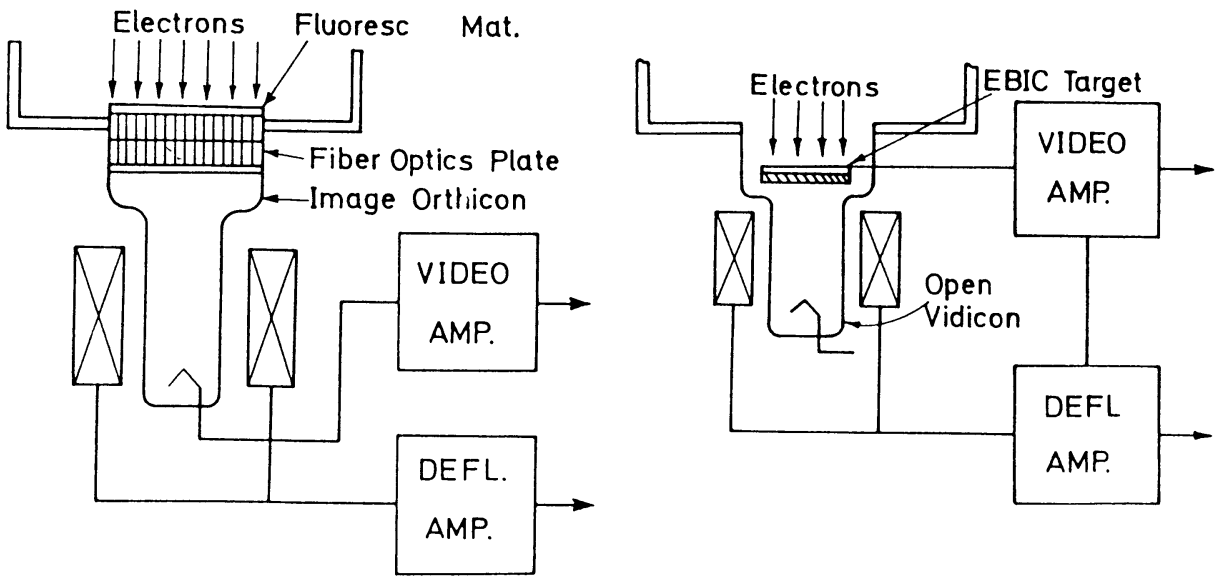

Fig. 4. - TV-VTR recording system: a) indirect type using fiber plate coupling to transfer the image on fluorescent screen to TV target; b) direct type in which TV target receives imaging electrons directly.

Advantages of High Voltage Scanning Transmission Electron Microscope (:HV-STEM) and Possible Applications

\begin{tabular}{|l|l|l|l|l|}
\hline ADDITIONAL FEATURES & PRINCIPAL ADVANTAGES & SPECIMENS \\
\hline INCRE ASE D ACCE LE- & Possibility of Studying \\
RATING VOLTAGE \\
Damage in More Materials
\end{tabular}

Fig. 5. - Advantageous features of High Voltage Scanning Transmission Electron Microscope (HV-STEM) and possible applications. 




Fig. 6. - Sectional view of model H-1250ST HV-STEM. 
6 indicates a sectional view of the model H-1250ST HV-STEM at Nagoya university. In this microscope, FE-gun was equipped to increase the brightness of the electron source and a vacuum better than $10^{-10}$ Torr was necessitated to equip the FE-gun. Construction was successfully accomplished and a bright scanning electron beam of about $0.5 \mathrm{~nm}$ was obtained. The expected advantages were evidenced and successful applications to in-situ experiments were made [21].

\section{Application of high time- and space- resolution techniques.}

As for the studies necessitating high time-resolutin, the introduction of TV-VTR system to HV insitu experiments by our group [5] enabled us to record at the speed of 30 frames/sec ( 60 fields/sec) dynamic behaviour of dislocations continuously and useful results were obtained in the following subjects: (a) mobility of edge and screw dislocations in bcc metals and $\beta \mathrm{CuZn}$ [23]. Figure 7 illustrates mobility data (dislocation velocity versus resolved shear stress) obtained by observing directly moving dislocations, and table I indicates mobility parameters $m$ and $D$ of a dislocation, where $R T$ means room temperature, $s$ screw component and $e$ edge component. (b) dislocation sources, mechanism and rate of dislocation multiplication [7, 23], (c) interactin of a moving dislocation with obstacles like forest dislocations, cell wall, interstitial atoms, precipitates and nonmetallic inclusions etc. [17, 24], (d) formation mechanism of anomalous slip in purified bcc metals $[17,25,26]$, (e) visualization of dislocation motions such as flip-flop motion of edge dipoles, shuttling motion of dislocations and formation of wall structures under alternating stress [17, 19], (f) mechanism of crack propagation and observation of dislocation free region in front of propagating microcrack in iron [27], (g) dislocation velocities during creep deformation [28, 29].

Table I. - Mobility parameter $m$ and $D$ of dislocations moving at RT (Room Temperature). s: screw component, e: edge component, $m$ : exponent of and $D$ in $\left.\langle v\rangle . /\rangle v_{0}\right\rangle=(\tau / D)^{\mathrm{m}}$ are dependent on the kind and physical state of materials. If $\left\langle v_{0}\right\rangle$ is assumed to be $10^{-2} \mathrm{~m} / \mathrm{s}$, the value $D$ corresponds to the stress value necessary for moving a dislocation at the speed of $10^{-2} \mathrm{~m} / \mathrm{s}$. Velocities are mostly measured with dislocation loops expanding under the applied stress near yield point.

\begin{tabular}{lrc}
\hline \hline Specimen & $m$ & $D / \mathrm{Pa}$ \\
\hline Mo $(R T s)$ & 4.8 & $6.8 \times 10^{7}$ \\
Mo $(150 \mathrm{~K} s)$ & 7.4 & $5.3 \times 10^{8}$ \\
Mo $(150 \mathrm{~K} e)$ & 14.2 & $1.7 \times 10^{8}$ \\
$\mathrm{Fe}(R T s)$ & 3.5 & $2.0 \times 10^{8}$ \\
$\mathrm{Fe}(150 \mathrm{~K} s)$ & 3.5 & $1.4 \times 10^{9}$ \\
$\mathrm{Fe}(150 \mathrm{~K} e)$ & 3.1 & $9.0 \times 10^{8}$ \\
$\mathrm{Fe}-3 \% \mathrm{Si}(R T e)$ & 34.5 & $1.6 \times 10^{8}$ \\
$\beta-\mathrm{CuZn}(550 \mathrm{Ke} e)$ & 1.3 & $5.2 \times 10^{10}$ \\
\hline \hline
\end{tabular}

$\dagger$ In $\langle v\rangle /\left\langle v_{0}\right\rangle=(\tau / D)^{m}$, the mobility parameters $m$ and $D$ are dependent on the kind and physical state of materials. If $\left\langle v_{0}\right\rangle$ is assumed to be $10^{-2} \mathrm{~m} / \mathrm{s}$, the value of $D$ corresponds to the stress value necessary for moving a dislocation at the speed of $10^{-2} \mathrm{~m} \cdot \mathrm{s}^{-1}$. 


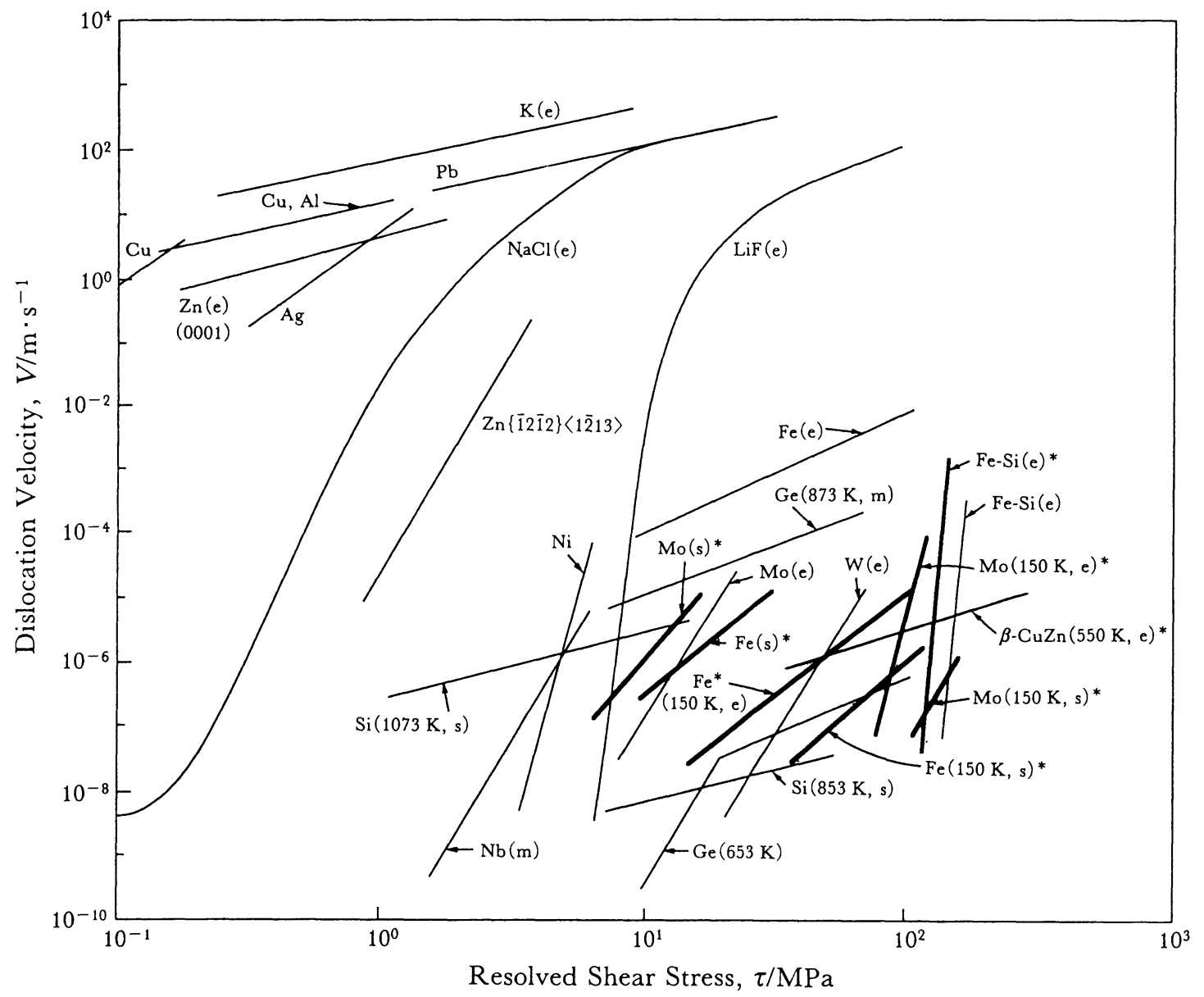

Fig. 7. - Mobility (dislocation velocity versus resolved shear stress) measured by observing directly moving dislocations in thick specimens. Bold lines and * marks represent the data of the present experiments. Other fine lines are data obtained by etch-pit method and others at room temperature.

As for the studies necessitating high-space resolution: (a) temperature dependence of stacking fault energies in $\mathrm{Cu}, \mathrm{Ag}$, their alloys (cf. Fig. 8) [30], (b) segregation of solute atoms to extended dislocation in fcc alloys [31], (c) non-conservative motion of extended jogs along a dissociated dislocation [32], (d) formation mechanism of a helical dislocation from an extended dislocation [33], (e) mechanism of climb motion of an extended dislocation [32, 33], (f) irradiation induced segregatin of solute atoms to dislocations [33], (g) formation of blister-like defects in $\mathrm{Al}$ under a high dose of electron bombardment using an environmental cell containing air [34], (h) crystallization process of amorphous materials and amorphizatin of crystalline materials under electronirradiation [35], (i) atomic structure of solid-liquid interface in InSb [36] etc.

\section{Conclusion.}

Recent development of in-situ experiments in a HVEM enabled us to observe various phenomena which are induced, in a controlled manner, in a specimen being examined in a HVEM, and 



Fig. 8. - Temperature dependence of stacking-fault energy (S.F.E. $\gamma \mathrm{mJm}^{-2}$ ) in pure $\mathrm{Ag}$. $\mathrm{Ag}$-Al alloys (a), and $\mathrm{d} \gamma / d T$ versus e/a obtained with $\mathrm{Ag}-\mathrm{Al}, \mathrm{Ag}-\mathrm{Sn}, \mathrm{Ag}-\mathrm{Sb}, \mathrm{Ag}-\mathrm{In}$ and $\mathrm{Cu}-\mathrm{Al}$ alloys.

many useful and original informations in materials science have been obtained. Further improvements of a dynamic recording system and in-situ specimen-treatment devices will contribute more to our understanding of the behavior and property of materials. Use of damage-rate reduced 
observation by STEM-mode EM and dynamic stereoscopic observation by HV-STEM should be recommended. Use of electron holography for observing three dimensional structure of crystalline materials as well as biomedical polymer should be recommended too. The combined use of stereoscopic technique for structural and microchemical analysis with in-situ experiments inside an environmental cell will open the way for a new field of research.

\section{References}

[1] Uyeda R., Nonoyama M. and Imura T., Proc. 6th Inter. Congr. EM, 6 (1966) p. 113.

[2] Fujita H., ibid., p. 289, and J. Phys. Soc. Jpn. 26 (1969) p. 331.

[3] Jouffrey B., Phys. Stat. Soli. (a) 55 (1979) 549.

[4] WiLsDORF H.G.F. (on behalf of T. Imura, H. Saka and N. Yukawa) Micron 1 (1969) p. 239 and p. 274.

[5] Imura T., SaKa H. and Yukawa N., J. Phys. Soc. Jpn. 26 (1969) p. 1327.

[6] SAKa H. and Imura T., J. Phys. Soc. Jpn. 32 (1972) pp. 702-718.

[7] ImURA T., Electron Microsc. Struct. Mater., G. Thomas et al. Eds., Univ. California Press 5 (1979) pp. 104-132.

[8] ButLer E.P., Progress Phys. 42 (1979) pp. 833-889.

[9] KUBIN L.P. and MARTIN J.L., Proc. 5th Int. Conf. on the Strength of Metals and Alloys (Aachen, Aug. 27-31, 1979) pp. 1639-1659.

[10] KiRITANi M., Proc. 5th Int. Conf. on HVEM (Kyoto, 1977) p. 505.

[11] Urban K., High Voltage Electron Microsc., P.R. Swann et al. Eds., Academic Press London (1974) p. 356, Microscopie Electronique à Haute Tension, B. Jouffrey Ed., Société Française de Microscopie Electronique (Paris, 1975) p. 159.

[12] Martin J.L. and Kubin L.P., Ultra Microsc. 3 (1978) 215, Phys. Stat. Soli. (a) 56 (1979) 487.

[13] IMURA T. and FujITA H., J. Electron. Microsc. 28 supplement (1979) p. 33.

[14] IMURA T., Solid State Phys. 4 (1967) p. 208 \& Butsuri (1970) p. 815 (in Japanese).

[15] ImUra T., SaKa H. , Doi M. and OKamoto N., Jpn. J. Appl. Phys. 10 (1971) p. 654.

[16] SaKa H., Todokoro H., Ashikawa M. and ImURA T., J. Phys. Soc. Jpn. 31 (1971) p. 1849.

[17] IMURA T. and SAKA H., Mem. Faculty Eng. Nagoya Unive. 28 (1976) pp. 54-112.

[18] SAKA H., NODA M. and IMURA T., Crys. Latticd Defects 4 (1973) p. 45.

[19] Yamamoto A., SaKa H., Noda K. and Imura T., Jpn. J. Appl. Phys. 15 (1976) p. 1977.

[20] IMURA T., In Situ Experiments with HVEM (Osaka Univ., 1985) pp. 381-397.

[21] HiRsCh P.B., Electron Microsc. (Leiden) P. Brederoo et al. Eds., 1 '1980) p. 146.

[22] IMURA T., Proc. 11th Int. Congr. Electron Microsc., 2 (1986) pp. 1033-1036.

[23] IMURA T., Mater. Trans. JIM 32 (1991) pp. 793-806.

[24] Kubin L.P. and LouChet F., Philos. Mag. A38 (1978) pp. 205-221.

[25] SaKa H., Noda K., Imura T., Matsui H. and Kimura H., Philos. Mag. A34 (1976) pp. 33-48.

[26] LOUCHET F. and KUBIN L.P., Scr. Met. 9 (1975b) 911.

[27] Ohr J.M., SaKa H., Zhu Y. and ImUra T., Philos. Mag. A57 (1988) p. 677.

[28] SAKA H., Sueki Y. and ImURa T., Philos. Mag. A37 (1978) p. 273.

[29] Hale K.F., Henderson M. and IsHida Y., Proc. 5th Europ. Conf. Electron Microsc. (London: The Institute of Physics, 1972) p. 350.

[30] SaKa H., Kondo N. and ImURA T., Philos. Mag. A47 (1983) 857.

[31] SAKA H., Kondo N. and KibA N., Philos. Mag. A44 (1981) 1213.

[32] Cherns D., Hirsch P.B. and SaKa H., Proc. Roy. Soc., A371 (1980) p. 213.

[33] SAKA H. and IMURA T., Proc. 10th Int. Congr. HVEM (Hamburg, 1982) pp. 481-488.

[34] JESSER W.A., NOHARA A., NishINO Y. and IMURA T., Kristall u. Technik. 14 (1979) 1219.

[35] DoI M. and ImURA T., Proc. 1st Int. Seminar on Solute Defect Interaction (1986) p. 327.

[36] SaKa H., Sakai R., Kamino T. and ImUra T., Philos. Mag. A52 (1985) p. 29. 